\title{
PENERAPAN REVIEW KRITIS ARTIKEL ILMIAH DALAM PERKULIAHAN METODOLOGI PENELITIAN
}

\author{
Setyo Eko Atmojo, Beny Dwi Lukitoaji \\ Surel: setyoekoatmojo@yahoo.co.id
}

\begin{abstract}
The purpose of this study was to improve the mastery of the concept of research methodology in undergraduate students of elementary school teacher education, the Faculty of Teacher Training and Education, Universitas PGRI Yogyakarta. This research method is a classroom action research which consists of two cycles where each cycle consists of four meetings. The subjects of this study were students of semester VI class A3-17 consisting of 40 students. This research was conducted in the even semester of 2019/2020 from February 2020 to March 2020. The results showed mastery of the concept of research methodology where $>80 \%$ of students mastered the concept of research methodology well. In addition,> $80 \%$ of students responded positively to learning and 36 out of 40 students received good and excellent scores in the assessment of research proposals as the final product of the research methodology course.
\end{abstract}

Keywords: Critical Review, Scientific Articles, Research Methodology Concept

\begin{abstract}
ABSTRAK
Tujuan penelitian ini adalah meningkatkan penguasaaan konsep metodologi penelitian pada mahasiswa program sarjana pendidikan guru sekolah dasar Fakultas Keguruan dan Ilmu Pendidikan Universitas PGRI Yogyakarta. Metode penelitian ini adalah penelitian tindakan kelas yang terdiri dari dua siklus dimana setiap siklus terdiri dari empat kali pertemuan. Subjek penelitian ini adalah mahasiswa semester VI kelas A3-17 yang terdiri dari 40 mahasiswa. Penelitian ini dilaksanakan pada semester genap tahun 2019/2020 pada bulan Februari 2020 hingga Maret 2020. Hasil penelitian menunjukkan penguasaan konsep metodologi penelitian dimana $>80 \%$ mahasiswa menguasai konsep metodologi penelitian dengan baik. Selain itu $>80 \%$ mahasiswa memberikan respon positif terhadap pembelajaran dan 36 dari 40 mahasiswa memperoleh nilai yang baik dan sangat baik dalam penilaian proposal penelitian sebagai produk akhir mata kuliah metodologi penelitian.
\end{abstract}

Kata Kunci: Review Kritis, Artikel Ilmiah, Konsep Metodologi Penelitian

\section{PENDAHULUAN}

Metodologi penelitian adalah salah satu mata kuliah wajib yang harus ditempuh oleh mahasiswa S1 Pendidikan Guru Sekolah Dasar di Fakultas Keguruan dan Ilmu Pendidikan Universitas PGRI Yogyakarta. Mata kuliah ini bertujaun untuk membekali mahasiswa tentang metodologi penelitian agar tidak menemui kesulitan dalam penyusunan tugas akhir atau skripsi. Kegiatan perkuliahan metodologi penelitian yang terjadi selama ini masih bersifat pemberian informasi langkah langkah penelitian secara teoritis sehingga kurang mendalam dan mahasiswa sulit memahami langkah langkah penelitian. Pendekatan penelitian secara umum 
dibagi dalam dua pendekatan yaitu pendekatan kuantitatif dan kualitatif (Anggito, A., \& Setiawan, n.d.). Pendekatan penelitian kuantitatif ini terbagi dalam beberapa jenis penelitian antara lain eksperimen, survay dan korelasi. Sedangkan pendekatan kualitatif memiliki beberapa jenis penelitian antara lain studi kasus, deskriptif dan etnografi.

Berdasarkan hasil observasi awal terhadap kemampuan penguasaan konsep metodologi penelitian mahasiswa diketahui bahwa sebanyak $87,5 \%$ mahasiswa memiliki penguasaan konsep yang rendah, 5,25\% memiliki penguasaan konsep sedang, $12,5 \%$ cukup dan $0 \%$ baik. Berdasarkan hasil tersebut maka diperlukan perhatian yang lebih dari dosen pengampu mata kuliah metodologi penelitian. Salah satu penyebab rendahnya penguasaan konsep metodologi penelitian mahasiswa ini adalah kurangnya mahasiswa melihat penerapan metodologi ini secara langsung dalam sebuah naskah baik artikel maupun skripsi atau laporan penelitian. Dalam sebuah penelitian motodologi adalah merupakan bagian penting yang menggambarkan proses pelaksanaan penelitian. Bagian metodologi ini harus dikuasai dengan matang oleh mahasiswa agar tidak menemui kendala dalam pelaksanaan penelitian. Pentingnya penguasaaan metodologi penelitian ini menuntut perubahan pelaksanaan perkuliahan yang telah dilakukan selama ini. Salah satu cara meningkatkan penguasaan konsep metodologi penelitian adalah melalui penerapan review kritis artikel ilmiah dalam perkuliahan metodologi penelitian.

Kegiatan mereview adalah sebuah meringkas, meninjau dari beberapa sumber entah dari film, buku, berita dan lainnya (Ambarsari, 2011); (Susilo et al., 2018); (Bikas et al., 2016) beberapa hal yang sering direview anatar lain adalah review buku, review film, review produk dan lainnya. Dengan adanya kegiatan review mahasiswa dapat mengetahui kelebihan, kekurangan dan kualitas dari suatu karya atau produk. Tujuan dilakukan review adalah untuk memberi informasi kapada pembaca tentang suatu hal dan mengajaknya atau membuat pembaca semakin penasaran, kegiatan review ini sangat penting untuk pemasaran suatu produk tertentu (Kusumahati, 2014); (Triandini et al., 2019).

Pada penelitian ini kegiatan review dilakukan pada artikel jurnal ke-SD-an oleh mahasiswa prgram studi PGSD UPY. Kegiatan review artikel jurnal ini dilakukan dalam mata kuliah metodologi penelitian. Tujuan kegiatan review artikel jurnal Ke-SD-an ini adalah meningkatkan penguasaan konsep metodologi penelitian mahasiswa program sarjana pendidikan guru sekolah dasar sehingga memudahkan dalam proses penyusunan proposal dan tugas akhir atau skripsi.

\section{METODE PENELITIAN}

Penelitian ini adalah merupakan penelitian tindakan kelas yang dilakukan di prodi PGSD FKIP 
UPY. Subjek penelitian ini adalah mahasiswa semester VI kelas A3-17 yang terdiri dari 40 mahasiswa. Penelitian ini dilaksanakan pada semester genap tahun 2019/2020 pada bulan Februari 2020 hingga Maret
2020 dimana setiap siklus terdiri dari empat kali pertemuan. Penelitian tindakan kelas ini terdiri dari empat langkah yaitu perencanaan, tindakan, observasi dan refleksi (Sanjaya, n.d.).

Tabel 1. Jenis, Teknik, dan Instrumen Pengumpulan Data

\begin{tabular}{l|l|l|l}
\hline \multicolumn{1}{c|}{ Jenis Data } & \multicolumn{1}{c|}{$\begin{array}{c}\text { Teknik Pengumulan } \\
\text { Data }\end{array}$} & $\begin{array}{l}\text { Instrumen Pengumpulan } \\
\text { Data }\end{array}$ & \multicolumn{1}{c}{$\begin{array}{c}\text { Teknik Analisis } \\
\text { Data }\end{array}$} \\
\hline Aktivitas Mahasiswa & Observasi & $\begin{array}{l}\text { Lembar Abservasi } \\
\text { Aktivitas Mahasiswa }\end{array}$ & $\begin{array}{l}\text { Deskriptif } \\
\text { Persentase }\end{array}$ \\
\hline $\begin{array}{l}\text { Penguasaan Konsep } \\
\text { Metodologi } \\
\text { Penelitian }\end{array}$ & $\begin{array}{l}\text { Proyek Penyusunan } \\
\text { Proposal Penelitian }\end{array}$ & $\begin{array}{l}\text { Rubrik Proposal Penelitian } \\
\text { Priaian }\end{array}$ & $\begin{array}{l}\text { Deskriptif } \\
\text { Persentase }\end{array}$ \\
\hline Respon Mahasiswa & Angket & Lembar Angket Respon & $\begin{array}{l}\text { Deskriptif } \\
\text { Persentase }\end{array}$ \\
\hline
\end{tabular}

HASIL PENELITIAN DAN PEMBAHASAN

Kegiatan penelitian ini dimulai dari perencanaan. Daam kegiatan perencanaan ini dosen merencanakan kegiatan perkuliahan metode penelitian dengan implmentasi review kritis artikel jurnal ke-SD-an. Kegiatan pembelajaran ini dilaksanakan sebanyak dua sikulus dimana masing masing siklus terdiri dari empat pertemuan sehingga total kegiatan penelitian ini terdiri dari delapan kali pertemuan. Kegitan review artikel ini adalah melakukan telaah secara kritis pada artikel jurnal ke-SD-an dalam mata kuliah metodologi penelitian. Kegiatan telaah ini dilakukan untuk meningkatkan penguasaan konsep metodologi penelitian yang meliputi pendekatan penelitian, jenis penelitian, perencanaan penelitian, penyusunan instrumen, hingga teknik menganalisis data sesuai jenis dan pendekatan penelitian yang digunakan. Kegiatan mereview artikel ini sangat bermanfaat bagi mahasiswa dalam menemukan konsep konsep metodologi penelitian. Review artikel jurnal merupakan kritik akademis yang diterapkan pada publikasi ilmiah berupa artikel jurnal (Ibda, 2020); (Anwar Us \& Mahdayeni, 2019). Dalam publikasi akademis, artikel jurnal ilmiah adalah publikasi berkala yang dimaksudkan untuk memajukan kemajuan ilmu pengetahuan yang biasanya merupakan laporan dari kegiatan penelitian terbaru. Berdasarkan hasil analisis data terhadap aktivitas mahasiswa diketahui terjadi peningkatan aktivitas mahasiswa dalam proses review artikel. 
Setyo Eko Atmojo, Beny Dwi Lukitoaji : Penerapan ...

Tabel 2. Aktivitas Mahasiswa Dalam Pembelajaran

\begin{tabular}{l|c|c|c}
\hline \multicolumn{1}{c|}{ Aktivitas } & $\begin{array}{c}\text { Persentase } \\
\text { Siklus 1 }\end{array}$ & $\begin{array}{c}\text { Persentase } \\
\text { Siklus 2 }\end{array}$ & Peningkatan \\
\hline Menemukan Artikel ruang lingkup Ke-SD-an & 52 & 95 & 43 \\
\hline $\begin{array}{l}\text { Menemukan masalah penelitian dalam artikel } \\
\text { yang di review }\end{array}$ & 45 & 87,5 & 42,5 \\
\hline $\begin{array}{l}\text { Menemukan teknik pemecahan masalah } \\
\text { dalam artikel yang di review }\end{array}$ & 42,5 & 85 & 42,5 \\
\hline $\begin{array}{l}\text { Menemukan metodologi penelitian dalam } \\
\text { artikel yang di review }\end{array}$ & 47,5 & 90 & 42,5 \\
\hline $\begin{array}{l}\text { Menemukan hasil dan kesimpulan dalam } \\
\text { artikel yang di review }\end{array}$ & 42,5 & 92,5 & 50 \\
\hline $\begin{array}{l}\text { Menemukan ksesuaian antara tujuan, } \\
\text { rumusan masalah, metode penelitan, hasil } \\
\text { dan kesimpulan dalam artikel yang di review }\end{array}$ & 37,5 & 87,5 & 50 \\
\hline
\end{tabular}

Berdasarkan Tabel Aktivitas

Mahasiswa dalam Pembelajaran dapat diketahui bahwa terjadi peningkatan aktivitas mahasiswa dalam pembelajaran. Peningkatan aktivitas ini terjadi pada seluruh aspek kegiatan pembelajaran. Aktivitas dengan peningkatan paling rendah yaitu menemukan masalah, pemecahannya dan metode penelitian yang digunakan. Ketiga aspek tersebut memiliki peningkatan sebesar 42,5\% berada pada kategori peningkatan sedang. Sedangkan pada aspek menemukan ksesuaian antara tujuan, rumusan masalah, metode penelitan, hasil dan kesimpulan dalam artikel yang di review terjadi peningkatan sebesar $50 \%$ yang berada pada kategori sedang. Peningkatan ini terjadi karena dengan adanya analisis dan review dari artikel jurnal menjadi sebuah strategi cara mudah untuk menemukan esensi dari penelitian yang ada dalam artikel jurnal (Maharani et al., 2019); (Noge, 2019). Esensi dari sebuah penelitian adalah metode ilmiah. Karena hakikatnya penelitian merupakan proses sistematis untuk memecahkan masalah. Permasalahn dipecahkan menggunakan metode ilmiah. Metode ilmiah merupakan suatu proses yang berurutan yang berisiskan pendefinisian masalah, perumusan hipotesis, pnegumpulan data, serta analisis data (Fitrah, M. (2018).

Selanjutnya untuk mengetahui penguasaaan konsep metodologi peneitian mahasiswa ditugaskan untuk menyusun proposal penelitian sebagai implementasi hasil review artikel jurnal Ke-SD-an. Penilaian proposal ini menggunakan rubrik penilaian yang meliputi kelengkapan yang harus ada dalam proposal penelitian tertuama bagian metodologi penelitian. 
Tabel 3. Persentase Penguasaaan Konsep Metodologi Penelitian

\begin{tabular}{l|c|c|c}
\hline \multicolumn{1}{c|}{ Aspek Yang Dinilai } & $\begin{array}{c}\text { Persentase } \\
\text { Siklus 1 }\end{array}$ & $\begin{array}{c}\text { Persentase } \\
\text { Siklus 2 }\end{array}$ & Peningkaan \\
\hline Merumuskan masalah penelitian & 42,5 & 87,5 & 45 \\
\hline Menentukan tujuan penelitian & 40 & 87,5 & 47,5 \\
\hline Menentukan metode penelitian & 40 & 90 & 50 \\
\hline $\begin{array}{l}\text { Menentukan jenis data yang akan } \\
\text { dikumpukan }\end{array}$ & 37,5 & 85 & 47,5 \\
\hline Menentukan teknik pengumpulan data & 36 & 87,5 & 51,5 \\
\hline $\begin{array}{l}\text { Menentukan instrumen pengumpulen } \\
\text { data }\end{array}$ & 36,5 & 87,5 & 51 \\
\hline Menentukan teknik pengumpulan data & 32 & 87,5 & 55,5 \\
\hline $\begin{array}{l}\text { Kesesuaian antara jenis data, instrumen, } \\
\text { teknik pengumpulan data dan teknik } \\
\text { analisis data }\end{array}$ & 32 & 87,5 & 55,5 \\
\hline
\end{tabular}

Berdasarkan Tabel Persentase Penguasaan Konsep Metodologi Penelitian diketahui bahwa secara umum mahasiswa telah mampu merumuskan masalah, menentukan tujuan, dan metode penelitian dalam proposal penelitian yang telah disusun. Sedangkan pada bagian menentukan jenis data, teknik pengumpulan data, instrumen dan teknik analisis data mahasiswa masih kesulitan dalam menyesuaikan ketiga aspek tersebut. Melalui pembelajaran yang mengimplementasikan review artikel pada akhir siklus 2 mahasiswa telah mampu menguasai seluruh aspek penyusunan proposal dengan rata rata $>80 \%$ mahasiswa mampu menyusun aspek aspek proposal penelitian tersebut dengan baik.

Berdasarkan Tabel Persentase Penguasaan Konsep Metodologi Penelitian diketahui terjadi peningkatan persentase Penguasaaan Konsep Metodologi Penelitian dari siklus 1 ke siklus 2. Dumana pada seluruh aspek penilaian penguasaan konsep metodologi penelitian terjadi peningkatan $>40 \%$ yang berada pada kategori sedang. Terjadinya peningkatan ini disebabkan oleh implmentasi review artikel jurnal yang diterapkan dalam pembelajaran. kegiatan review artikel ini dapat membandingkan dengan mudah antara penelitian satu dengan penelitian yang lainnya.

Selain itu, melalui review artikel jurnal mahasiswa dapat dengan mudah menggali, menganalisis, serta menyimpulkan hasil penelitian dari artikel satu dengan artikel yang lainnya (Handayani et al., 2019); (Fitriyani, Y., Fauzi, I., \& Sari, 2020). Mahasiswa juga dapat dengan mudah menentukan metode yang tepat bagi penelitiannya karena telah melakukan riview sehingga mampu mengevaluasi menegnai kelebihan dan kekurangan suatu artikel jurnal.

$$
\text { Peningkatan penguasaan }
$$
konsep metodologi penelitian melalui implementasi review artikel ini direpon dengan baik oleh mahasiswa. 
Setyo Eko Atmojo, Beny Dwi Lukitoaji : Penerapan ...

Tabel 4. Respon Mahasiswa Terhadap Pembelajaran

\begin{tabular}{l|c|c}
\hline \multicolumn{1}{c|}{ Pernyataan } & \multicolumn{2}{c}{ Respon Mahasiswa } \\
\hline $\begin{array}{l}\text { Artikel dari jurnal tentang penelitian dan pembelajaran } \\
\text { ke-SD-an di sekolah penting sebagai sumber belajar }\end{array}$ & 33 & 7 \\
\hline $\begin{array}{l}\text { Setelah mereview artikel menjadi lebih memahami } \\
\text { permasalahan pembelajaran di sekolah dasar }\end{array}$ & 36 & 4 \\
\hline $\begin{array}{l}\text { Pengalaman nyata mereview artikel mempermudah } \\
\text { dalam menyusun proposal penelitian }\end{array}$ & 35 & 5 \\
\hline $\begin{array}{l}\text { Mata kuliah metodologi penelitian menjadi lebih } \\
\text { menarik setelah merevew artikel }\end{array}$ & 38 & 2 \\
\hline
\end{tabular}

Berdasarkan Tabel Respon Mahasiswa terhadap Pembelajaran diketahui bahwa > 80\% mahasiswa memberikan respon positif terhadap kegiatan pemeblajaran. Respon positif ini terlihat pada mahasiswa yang setuju terhdap proses pembelajaran metodologi penelitian dengan menerapkan review kritis artikel jurnal penddikan dan pembelajaran ke-SD-an.

\section{Pembahasan}

Permasalahan yang diatasi melalui penelitian ini berdasarkan hasil refleksi pelaksanaan pembelajaran mata kuliah Metodologi Penelitian di program sarjana pendidikan guru sekolah dasar bahwa mahasiswa dalam menyusun proposal penelitian sebagai tugas akhir mata kuliah tersebut belum sesuai harapan. Berdasarkan hal tersebut maka mahasiswa dalam penelitian harus diberi latihan untuk mereview artikel hasil penelitian sehingga diharapkan mampu menyusun rencana penelitian dalam bentuk proposal skripsi sekaligus terlatih menyusun artikel jurnal (Akhlis, I. Dewi, 2013). Artikel yang direview mahasiswa dibatasi pada permasalahan pendidikan dan pembelajaran ke-SD-an. Hasil review dimanfaatkan oleh mahasiswa sebagai bahan diskusi kelas untuk mempelajari berbagai metode yang telah digunakan untuk mengatasi permasalahan pendidikan dan pembelajaran ke-SD-an.

Berbagai kelemahan pada siklus satu, dijadikan bahan perbaikan dalam penelitian ini agar tujuan penelitian tercapai. Beberapa kegiatan untuk perbaikan siklus kedua yang dilakukan meliputi; 1) kegiatan mereview artikel dilakukan dirumah karena keterbatasan waktu; 2) diskusi difokuskan pada tema penelitian yang mendukung penulisan propsal skripsi mahasiswa; 3) mahasiswa harus dapat menemukan karakteristik suatu jenis penelitian agar mudah dalam menentukan metode enelitian yang tepat untuk mengatasi masalah; dan 4) mahasiswa harus menyiapkan referensi tambahan agar lebih mudah dalam membahas kelebihan dan kelemahan dari masing masing artikel yang direview.

Produk dari mata kuliah Metodologi Penelitian ini adalah proposal penelitian yang disusun 
secara individu. Berdasarkan hasil penilaian seperti Tabel 5. Hasil penilaian proposal penelitian yang disusun oleh mahasiswa diperoleh

Penilaian Proposal Penelitian

Mahasiswa berikut ini.

Tabel 5. Hasil Penilaian Proposal Penelitian Mahasiswa

\begin{tabular}{c|c|c}
\hline Nilai & Jumlah Mahasiswa & Kriteria \\
\hline $91-100$ & 3 & Sangat Baik \\
\hline $81-90$ & 33 & Baik \\
\hline $71-80$ & 4 & Cukup \\
\hline $61-70$ & 0 & Kurang \\
\hline$<60$ & 0 & Sangat Kurang \\
\hline
\end{tabular}

Berdasarkan Tabel Hasil Penilaian Proposal Penelitian Mahasiswa diketahui bahwa mahasiswa telah mampu menyusun proposal penelitian dengan baik. dimana berdasarkan hasil penliaian proposal diketahui bahwa 36 dari 40 mahasiswa memperoleh nilai yang baik dan sangat baik. hal tersebut menunjukkan bahwa kegiatan penelitian ini mampu untuk mengatasi permasalahan kesulitan mahasiswa dalam menguasai konsep metodologi penelitian yang berdampak pada kesulitan menyusun proposal penelitian. Melalui pembelajaran ini mahasiswa telah mampu menyusun proposal dengan baik dan lengkap mulai dari penentuan judul, rumusan masalah, tujuan, dan penyusunan metodologi penelitian. Mahasiswa telah mampu mensinkronkan antara rumusan, tujuan, jenis data, teknik pengumpulan data dan teknik analisis data dengan baik.

\section{SIMPULAN}

Berdasarkan data dan fakta dilapangan dapat disimpulkan bahwa implementasi review kritis artikel ilmiah dalam perkuliahan metodologi penelitian dapat dilakukan dengan baik dan memberikan peningkatan dalam penguasaan konsep metodologi penelitian dimana .> $80 \%$ mahasiswa menguasai konsep metodologi penelitian dengan baik. Berdasarkan angket respon menujukkan > $80 \%$ mahasiswa memberikan respon positif terhadap kegiatan pembelajaran. Dalam penyusunan proposal penelitian diketahui 36 dari 40 mahasiswa memperoleh nilai yang baik dan sangat baik.

\section{DAFTAR RUJUKAN}

Akhlis, I. Dewi, N. 2013. Jurnal Pendidikan IPA Indonesia. Jurnal Pendidikan IPA Indonesia, 2(2), 203-208.

Ambarsari, L.; H. 2011. Pendidikan Dasar. Pendidikan Dasar, 2(Penilaian), 2-6.

Anggito, A., \& Setiawan, J. 2018. M. penelitian kualitatif. C. J. (Jejak P. (n.d.). anggito.pdf.

Anwar Us, K., \& Mahdayeni, M. 2019. Penggunan E-Learning, 
E-Book, E-Journal dan Sistem Informasi Pendidikan Islam di Universitas Sriwijaya Palembang. INNOVATIO: Journal for Religious Innovation Studies, 19(1), 43-64. https://doi.org/10.30631/innovat io.v19i1.81

Bikas, H., Stavropoulos, P., \& Chryssolouris, G. 2016. Additive manufacturing methods and modeling approaches: A critical review. International Journal of Advanced Manufacturing Technology, 83(1-4), 389-405. https://doi.org/10.1007/s00170015-7576-2

Handayani, I., Febriyanto, E., \& Shofwatullah, M. 2019. SATINSains dan Teknologi Informasi Mesin Pencari Berbasis Search Engine Optimization ( SEO ) On Page. 5(1).

Ibda, H. 2020. Peningkatan Keterampilan Menulis Resensi Buku Ilmiah pada Mahasiswa Melalui Program Satu Semester Satu Resensi (Tuter Tensi). 2, 113.

Kusumahati, M. 2014. Keefektifan Model Course Review Horay Terhadap Peningkatan Hasil Belajar Ips. Journal of Elementary Education, 3(2), 16.

Maharani, D. A. M., Rahmawati, I., \& Sukamto, S. 2019. Peningkatan Aktivitas dan Hasil Belajar Tematik Siswa Melalui Strategi
Pembelajaran Team Quiz dan Media Teka Teki Silang. International Journal of Elementary Education, 3(2), 151-158.

Noge, M. D. 2019. Penerapan Model Pembelajaran Bilingual Preview-Review Berbasis EFlashcard Untuk Meningkatkan Aktivitas Dan Prestasi Belajar Bahasa Inggris Siswa Smp. Journal of Education Technology, 2(1), 13. https://doi.org/10.23887/jet.v2il .13801

Sanjaya, D. H. W. 2016. P. tindakan kelas. P. M. (n.d.). sanjaya.pdf.

Susilo, H., Zubaidah, S., Rachman, F., \& Sudrajat, A. K. 2018. Format Analisis Kritis Artikel Yang Berpotensi Mengembangkan Keterampilan Berpikir Kritis Mahasiswa. Jurnal Penelitian Pendidikan Matematika Dan Sains, 2(2). http://journal.unesa.ac.id/index. php/jppms/

Triandini, E., Jayanatha, S., Indrawan, A., Werla Putra, G., \& Iswara, B. 2019. Metode Systematic Literature Review untuk Identifikasi Platform dan Metode Pengembangan Sistem Informasi di Indonesia. Indonesian Journal of Information Systems, 1(2), 63. https://doi.org/10.24002/ijis.v1i 2.1916. 

